\title{
A Field Survey on Anthelmintic Resistance in Equine Small Strongyles in Norway
}

\author{
By C.F. Ihler
}

Department of Large Animal Sciences, Norwegian College of Veterinary Medicine. Oslo, Norway.

\begin{abstract}
Ihler, C. F.: A field survey on anthelmintic resistance in equine small strongyles in Norway. Acta vet. scand. 1995, 36, 135-143. - A field survey at 17 stables involving 221 horses was performed to evaluate the presence of anthelmintic resistance in the equine small strongyles (cyathostomes). The horses were allocated into treatment groups, and resistance to fenbendazole (FBZ), pyrantel pamoate (PYR) and ivermectin (IVM) was tested by the faecal egg count reduction test (FECR-test). Faecal samples were collected at the time of treatment, 14 days post treatment and 90 days post treatment.

Resistance to FBZ, which was defined as a faecal egg count reduction $<95 \%$, was found in 14 out of 17 stables. In 2 of the 14 stables the egg reductions were close to the limit of $95 \%, 91$ and $93 \%$, respectively. In 1 stable the egg reductions indicated resistance to PYR as well as detection of resistance to FBZ, 94\% reduction for PYR and $85 \%$ for FBZ. No signs of resistance were detected to IVM.

The investigation was performed in late autumn and winter, and due to the climatic conditions and cleaning procedures in the stables no reinfection took place during this period. The faecal egg count reduction from treatment till day 90 post treatment was used as an expression of the effect of PYR and IVM on the early stage (hypobiotic), late third stage and fourth stage larvae in the gut wall. This was justified because there was no reinfection and because the 14 day post treatment egg counts were zero or close to zero for the PYR and IVM treatment groups. The effects of PYR and IVM on the larval stages were compared and no statistically significant differences were found.
\end{abstract}

horse; anthelmintic efficacy; cyathostomes; fenbendazole; ivermectin; pyrantel; larvacidal effect; parasite control.

\section{Introduction}

Resistance to anthelmintics in gastrointestinal nematodes of domestic animals is considered a major problem in the medical control of parasite infections (Taylor 1992, Ihler 1992). Prichard et al. (1980) have defined anthelmintic resistance as "a significant increase in the ability of individuals within a strain to tolerate doses of a compound (toxicant) which would prove lethal to the majority of individuals in a normal population of the same species." Resistance is reported in the gastrointestinal strongyle nematodes in horses, small rumi- nants, pigs and cattle (Taylor 1992, Ihler 1992).

According to their mode of action, the broad spectrum anthelmintics are grouped in 3 classes: (1) the benzimidazoles, (11) the levamisoles and morantel/pyrantel and (111) the ivermectins. Resistance to all these classes of drugs has been described in gastrointestinal nematode species of domestic animals (Ihler 1992). In the horse, resistance has only been reported to phenothiazine and the benzimidazoles in the small strongyles (cyathostomes). With the reports of phenothiazin resistance in 
small strongyles, Gibson (1960) and Drudge \& Elam (1961) were the first to describe resistance in equine parasites. There are reports on benzimidazole resistance in small strongyles from many countries, i.e., Kentucky, USA (Drudge \& Lyons 1965), England (Round et al. 1974), Canada (Slocombe \& Cote 1977), Australia (Barger \& Lisle 1979), Germany (Bauer et al. 1986), Belgium (Dorny et al. 1988) and Brazil (Pereira et al. 1991). There are also reports on resistance in small strongyles from the Scandinavian countries. From Denmark, Bjørn et al. (1991) have described resistance in small strongyles to benzimidazoles. Reports from Sweden (Nilsson et al. 1989) and Norway (Helle 1986) have also indicated resistance to benzimidazoles in small strongyles.

Different methods, including both in vivo and in vitro methods, have been used to detect anthelmintic resistance. For reviews see Johansen (1989) and Taylor (1992). For detection of anthelmintic resistance in equine nematodes the faecal egg count reduction test (FECRtest) is widely used.

The main purpose of this investigation was to estimate the presence of resistance to the commonly used anthelmintics in horses in Norway, and further to obtain information on the efficacy of the anthelmintics against the larval stages of the cyathostomes.

\section{Materials and methods}

\section{Selection of stables and horses}

The present study included 17 stables and a total number of 221 horses. Both Standardbred and Norwegian coldblooded trotters as well as Thoroughbred and various races of pleasure horses were represented. All stables were located in Southeast Norway.

The study was performed from late September 1991 till mid February 1992. The horses were housed during the night, and spent some time in paddocks during the day. No grass was available in any paddock. The horses were fed inside on hay and concentrates. Faeces were removed daily in all stables, and once a week the boxes were totally cleaned and new bedding put in.

Horses of all ages were included. The ages ranged from 6 months to 16 years. Animals that stayed at a stable for less than 6 months and horses treated with anthelmintics within the last 3 months were excluded. All the 221 horses included in the present study had egg counts of at least 30 eggs per gram (EPG) of the strongyle type at the time of treatment. Twenty-five horses with lower EPG were excluded, but not replaced in the randomization procedure.

\section{Experimental design}

In 13 of the 17 stables, which had more than 10 horses, the horses were randomly allocated into blocks of 3 animals. After collecting faecal samples, the horses within each block randomly received fenbendazole (FBZ), pyrantel pamoate (PYR) or ivermectin (IVM) as treatment. When a block consisted of 1 or 2 horses, i.e., when the total number of horses in a stable could not be divided by 3 , a random selection of treatment was used. If the stable contained 10 or less horses, the horses were divided into blocks of 2 animals. One horse in these blocks were treated with FBZ and the other with either PYR or IVM. The dose rates were as recommended by the manufacturers: FBZ (Panacur ${ }^{\circledR}$, Hoechst) 7.5 mg per kg, PYR (Banminth $^{\circledR}$, Pfizer) $19 \mathrm{mg}$ per kg and IVM (Ivomec $^{\circledR}$, MSD) $0.2 \mathrm{mg}$ per kg. All treatments were given orally and only paste formulations were used.

The body weights were estimated by using the formula: Body weight in $\mathrm{kg}=\mathrm{B} \times 6.25-625$, where $B$ is the circumference of the horse 
measured just behind the fore-limbs. The horses did not receive any additional anthelmintic treatment during the investigation period.

\section{Parasitological methods}

Faecal samples were collected directly from rectum if fresh faeces were not available, put into plastic bags, labeled and stored at $4^{\circ} \mathrm{C}$ until the parasitological examination. Faeces were collected at the time of treatment and at day 14 and 90 post treatment.

The faecal egg counts were performed using a modified McMaster technique with saturated $\mathrm{NaCl}$-solution as flotation medium. A Universal egg-counting chamber described by Whitlock et al. (1980) was used for counting. The detection level of this method is 10 EPG. From all samples where strongyle eggs were detected, a larval culture was made. $20-30 \mathrm{~g}$ of each sample were incubated at $26^{\circ} \mathrm{C}$ for 7 days. The third stage larvae were collected using a Baerman-technique, and differentiated according to their morphological criteria (Lichtenfels 1975). From all cultures 100 larvae were examined. If the total number in a culture was less than 100 , all larvae were examined.

\section{Calculations and statistical methods}

The effects of the different anthelmintics were estimated by using the faecal egg count reduction test (FECR-test). Egg reductions were calculated as arithmetic means of the egg reductions for each treatment group in each stable. A working group in Australia has formulated a definition based on the FECR-test (Anon 1989). Anthelmintic resistance is present if: 1) Faecal egg reduction after treatment is less than $95 \%$ and 2) the lower $95 \%$ confidence limit of the reduction is less than $90 \%$. In the present study this definition is used.
The faecal egg count reductions from treatment till day 90 post treatment (FECR3) was used as an expression of the larvacidal effect of PYR and IVM ( see discussion), and calculated as arithmetic means. These reduction values are given as means for all horses treated with the same anthelmintic. The nonparametric Kruskal-Wallis test was used to test for a difference in FECR3-values between the PYR and the IVM treatment groups.

A questionnaire study on the use of anthelmintics was performed to obtain data on treatment frequencies, preparations used and alternation programs between different anthelmintics in the stables.

\section{Results}

The results of the FECR-test are presented in Table 1. According to the definition, resistance to FBZ was found in 14 of the 17 stables. In 2 of these stables the FECR-values were close to the limit of $95 \%, 91$ and $93 \%$, respectively. The FECR-values for PYR and IVM were $95 \%$ or higher, except for stable 16 . In this stable there were indications of a reduced effect of PYR (94\%). For IVM the egg count reductions were $100 \%$ in all tested stables except stable 15 (96\%).

Larval cultivation revealed third stage larvae of Strongylus vulgaris in 16 horses from 8 different stables at the time of treatment. In these horses the number of $S$. vulgaris larvae ranged from $2-8 \%$ of the total number of strongyle larvae. All treatment groups were represented among these horses. In the 14 day post treatment samples only cyathostome larvae were detected. At day 90 post treatment $S$. vulgaris larvae were detected in 6 horses. In 4 of these horses no $S$. vulgaris were found at treatment.

At the time of treatment eggs from Parascaris equorum were found in 31 horses from 7 dif- 
Table 1. Faecal egg reductions for fenbendazole, pyrantel pamoate and ivermectin treatments in 17 stables.

\begin{tabular}{|c|c|c|c|c|c|c|}
\hline \multirow{2}{*}{$\begin{array}{l}\text { Stable } \\
\text { number }\end{array}$} & \multicolumn{2}{|c|}{ Fenbendazole } & \multicolumn{2}{|c|}{ Pyrantel pamoate } & \multicolumn{2}{|c|}{ Ivermectin } \\
\hline & $\mathbf{n}$ & FECR (lcl) & $\mathrm{n}$ & FECR (lcl) & $\mathrm{n}$ & FECR (lcl) \\
\hline 1 & 3 & $45(-84)$ & 4 & $100(99)$ & & \\
\hline 2 & 4 & $100(100)$ & & & 4 & $100(100)$ \\
\hline 3 & 8 & $89(67)$ & 8 & $100(100)$ & 6 & $100(100)$ \\
\hline 4 & 5 & $79(24)$ & 5 & $100(100)$ & 4 & $100(100)$ \\
\hline 5 & 6 & $72(32)$ & 7 & $100(99)$ & 5 & $100(100)$ \\
\hline 6 & 4 & $81(58)$ & 3 & $100(100)$ & 3 & $100(100)$ \\
\hline 7 & 5 & $95(91)$ & 4 & $100(99)$ & 3 & $100(100)$ \\
\hline 8 & 5 & $91(83)$ & 6 & $100(99)$ & 5 & $100(100)$ \\
\hline 9 & 3 & $-141(-840)$ & & & 5 & $100(100)$ \\
\hline 10 & 4 & $93(81)$ & 3 & $99(96)$ & 5 & $100(100)$ \\
\hline 11 & 4 & $74(40)$ & 4 & $97(90)$ & 4 & $100(100)$ \\
\hline 12 & 6 & $73(42)$ & 5 & $100(99)$ & 4 & $100(100)$ \\
\hline 13 & 3 & $80(32)$ & 4 & $100(99)$ & 7 & $100(100)$ \\
\hline 14 & 5 & $64(21)$ & 5 & $100(100)$ & & \\
\hline 15 & 7 & 71 (19) & 3 & $100(97)$ & 3 & $96(84)$ \\
\hline 16 & 7 & $85(60)$ & 6 & $94(86)$ & 3 & $100(100)$ \\
\hline 17 & 5 & $95(90)$ & 5 & $100(99)$ & 4 & $100(100)$ \\
\hline
\end{tabular}

FECR = Arithmetic mean of faecal egg reductions $\mathrm{lcl}=$ lower $95 \%$ confidence limit of FECR $\mathrm{n}=$ number of horses in treatment group.

ferent stables. At day 14 post treatment no parascaris eggs were detected, and at day 90 post treatment parascaris eggs were present in 10 horses. All treatment groups were represented among these 10 horses and all of these horses had faecal outputs of $P$. equorum at treatment. Eggs from other gastrointestinal nematodes or cestodes were not detected in any of the faecal samples.

The mean EPG-values at the time of treatment and at 14 and 90 days post treatment are shown in Fig. 1. For all treatment groups the EPG-values increased from day 14 till day 90 post treatment.

The egg reductions from treatment to day 90 post treatment for the PYR and IVM treatment groups are presented in Table 2. The Kruskall-Wallis test showed no statistically significant difference in FECR3 between these treatment groups, regardless of whether all horses were used for calculations or the stables were divided into FBZ-resistant and non-resistant stables.

The questionnaire study showed similar parasite control programs in most of the stables. The horses were treated from 3 to 5 times per year in all stables, on average 3.8 per year. All stables except 3 used IVM during winter every year for the control of Gastrophilus spp. In all stables, with the exception of stables 6,9 and 11 , an alternation of drugs was used. In these 3 stables FBZ had been used for all treatments for the last 6 or 7 years. The alternation programs, however, differed. In some stables drugs were changed for every treatment. In others a new anthelmintic was used every year and in some 2 or 3 years elapsed before a new drug was introduced. The new anthelmintic in an alternation strategy always belonged to another class. 


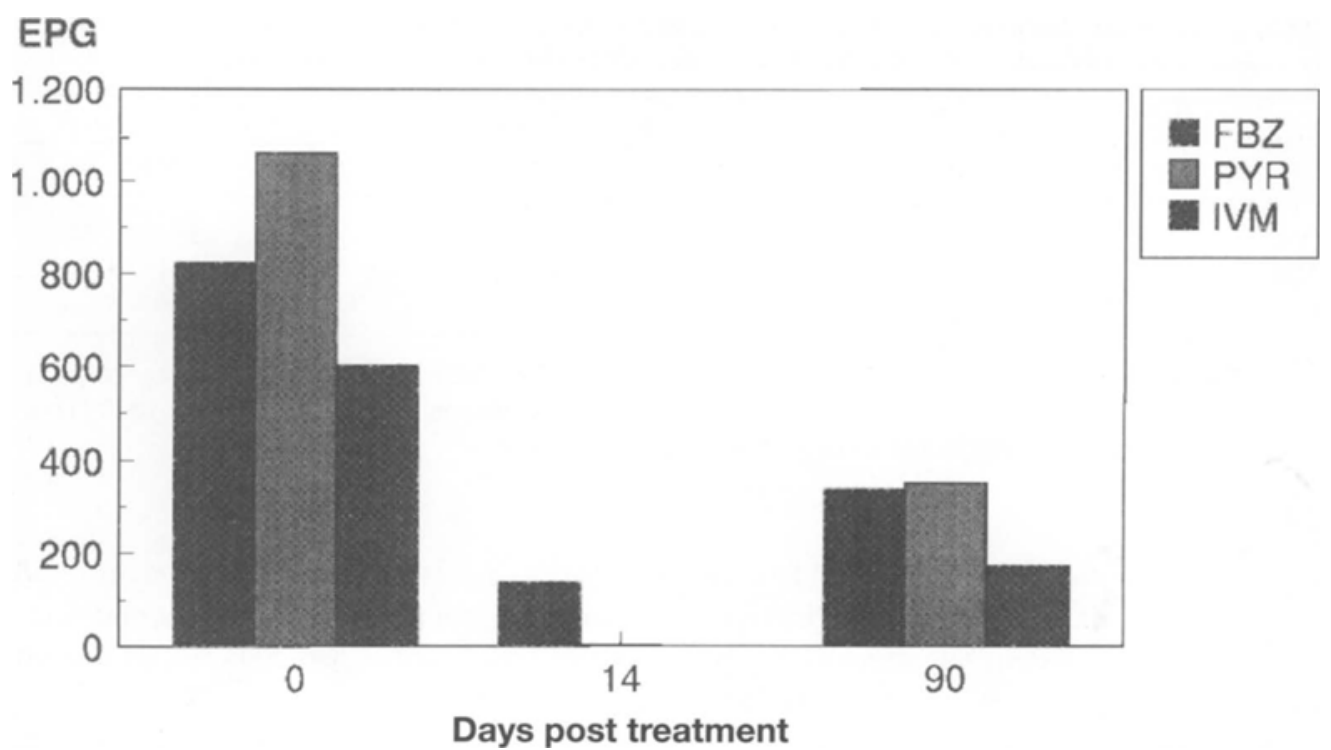

Figure 1. Arithmetic means of faecal egg counts for all horses at the time of treatment and 14 and 90 days post treatment for the fenbendazole (FBZ), pyrantel pamoate (PYR) and ivermectin (IVM) treatment groups.

\section{Discussion}

In the present study the FECR-test was used to assess resistance in small strongyles to 3 classes of anthelmintics. Dash et al. (1988) and McKenna (1990) have discussed whether to use arithmetic or geometric means of the egg counts in a FECR-test. Both concluded that the arithmetic means gave the most correct FECR-values. Accordingly, the arithmetic means were used in this study.

Although this study shows FBZ-resistance in 14 of the 17 stables, the FECR-values in the resistant stables are higher than reported from other studies (Bauer et al. 1986, Bjørn et al. 1991, Fisher at al. 1992). Even though the experimental designs of these studies are different, it is still relevant to compare the results. The higher FECR-values may be explained by differences in anthelmintic control programs. Less frequent treatments and an al- ternation between anthelmintics of different classes will reduce the development of resistance (Kelly et al. 1981), and probably preserve the efficacy of benzimidazole treatment at a high level, even if resistance, as defined in 'Materials and Methods' is present. Bjørn et al. (1991) found a mean treatment frequency of 7.1 treatments pr. year, compared to 3.8 in this study.

The questionnaire study showed further that alternation between drugs was widely used. In stable 9, where FBZ had been used to a large extent during the last 6 years, no effect of benzimidazoles on the faecal egg output was detected. In addition, the present study also shows that a shift to new classes of anthelmintics is more common than in the Danish study, where alternations between drugs within the same class were frequent. In Norway anthelmintics must be prescribed by a veterinarian, 
Table 2. The egg reductions from treatment till day 90 post treatment in the pyrantel pamoate and ivermectin treatment groups for all stables, the fenbendazole-resistant stables and fenbendazole-non-resistant stables.

\begin{tabular}{|c|c|c|c|c|c|c|c|c|c|}
\hline \multirow{2}{*}{ Drug } & \multicolumn{3}{|c|}{ All stables } & \multicolumn{3}{|c|}{ Resistant stables } & \multicolumn{3}{|c|}{ Non-resistant stables } \\
\hline & $\mathrm{n}$ & FECR3 & SD & $\mathrm{n}$ & FECR3 & SD & $\mathrm{n}$ & FECR3 & SD \\
\hline PYR & 72 & 22.6 & 121.5 & 63 & 17.8 & 126.8 & 9 & 55.3 & 54.8 \\
\hline IVM & 65 & 24.2 & 161.2 & 53 & 26.4 & 175.4 & 11 & 13.1 & 74.1 \\
\hline $\mathrm{p}$ & & 0.69 & & & 0.35 & & & 0.16 & \\
\hline
\end{tabular}

PYR $=$ Pyrantel. IVM = Ivermectin. $\mathrm{n}=$ number of animals. FECR3 = Arithmetic mean of faecal egg count reduction from treatment till day 90 post treatment. SD = Standard deviation of FECR3. $p=$ The $p$-values comparing the 2 treatment groups by the Kruskall-Wallis Test.

which allows control of distribution and use of the drugs. The involvment of veterinarians may explain the extent of alternation observed, and the more frequent use of new classes of anthelmintics. This is important as drugs belonging to the same class normally show side resistance (Lacey 1988). Although, oxibendazole is observed to be an exception in small strongyles in horses (Bauer et al. 1986, Drudge \& Lyons 1979).

As reported in all previous studies, the present investigation only shows resistance in small strongyles. With the exception of stable 16, only FBZ-resistance was detected.

There are reports on resistance to all classes of anthelmintic drugs to strongyle nematodes (Borgsteede 1988, Anderson \& Lord 1979, Sangster et al. 1979, van Wyk et al. 1988, Giordano et al. 1988, Roepstorff et al. 1987). From these reports one might assume that occurrence of resistance to PYR and IVM in the cyathostomes is only a question of time. The reduced efficacy of PYR in stable 16 may be an indication of developing PYR-resistance. Recent studies from USA have also indicated PYR-resistance to small strongyles (Klei pers. comm.).

The presence of only cyathostome larvae at day 14 post treatment indicates a $100 \%$ effect on adult $S$. vulgaris. The reappearance of $S$. vulgaris eggs at day 90 post treatment in all treatment groups, futher indicates that none of the anthelmintics had $100 \%$ effect against $S$. vulgaris larvae.

In all horses where $S$. vulgaris were present, the numbers $S$. vulgaris larvae were low, ranging from 2 to $8 \%$ of the total strongyle larvae. Thus, for practical purposes, Fig. 1 represents small strongyle egg counts.

The egg counts were higher at day 90 than at day 14 post treatment for all treatment groups. The egg outputs at day 90 post treatment may have 3 different sources: 1) from adult cyathostomes that developed from third stage larvae taken up post treatment (reinfection); 2) from adult worms which survived treatment; or 3) from adult worms that had developed from larvae present in the host at the time of treatment. The latter source could either be encysted late third stage, fourth stage or hypobiotic third stage larvae. The investigation period (late autumn and winter) and the feeding and cleaning procedures in the stables reduced the possibilities of reinfection to a minimum. Thus, the EPGs at day 90 are suggested to be due to parasites already present in the host at treatment.

In the PYR and IVM treated horses the EPGvalues at 14 days post treatment were zero or close to zero. Thus, it may be concluded that 
eggs present at day 90 are due to developed larvae present at the time of treatment and that the egg reduction from treatment till day 90 post treatment can be used as an expression of the cyathostome larvacidal effect for PYR and IVM. The results of the egg reductions from treatment till day 90 were analyzed statistically and no significant differences were found between the 2 drugs.

For the FBZ-treated horses the EPGs of day 90 post treatment are of a more complicated nature. On the one hand we have the egg production from survived worms, on the other hand egg production from larvae that have moulted after treatment. It is known that worms present in the gut lumen will suppress the migration of the hypobiotic larvae into the lumen, and that removal of the adult population will stimulate this migration (Gibson 1953). It is difficult to asses the influence of these factors on the EPGs at day 90 for the FBZ-treatment group. Therefore, the egg reductions from treatment till day 90 will not be useful as an expression of the larvacidal effect of FBZ.

To obtain better information on egg outputs 90 days post treatment, it would have been desirable to have untreated control groups. However, for practical and ethical reasons, this was not possible.

The effect of drugs on hypobiotic early third stage larvae is considered doubtful (Uhlinger 1991, Eysker et al. 1991). Further, Eysker et al. (1992), Klei et al. (1993) and Xiao et al. (1994) found no evidence of IVM effect on late third stage and fourth stage cyathostome larvae. The present study, however, has not obtained information on the total effect against the larvae, but concludes that there are no statistically significant differences in this effect between PYR and IVM.

\section{Acknowledgements}

I thank Dr. Henrik Bjørn for help with the statistics and the manuscript. I also thank Miss Asbjørg Husdal for skillful assistance in the laboratory, and Dr. Oddvar Helle, Dr. Hallstein Grønstøl and Dr. Charles Press for their critical review of the manuscript. This study was supported by the Norwegian Research Counsil.

\section{References}

Anderson N, Lord V: Anthelmintic efficacy of oxfendazole, fenbendazole and levamisole against naturally acquired infections of Ostertagia ostertagi and Trichostrongylus axei in cattle. Aust. vet. J. 1979, 55, 158-162.

Anon: Report of the working party for the animal health committee of the standing committee on agriculture: Anthelmintic resistance. Waller PJ, (ed.) SCA Technical report series-no. 28, CSRIO Australia, East Melbourne 1989.

Barger IA, Lisle IA: Benzimidazole resistance in small strongyles of horses. Aust. vet. J. 1979, 55, 594-595.

Bauer C, Merkt JC, Janke-Grimm G, Burger HJ: Prevalence and control of benzimidazole resistant small strongyles in German thoroughbred studs. Vet. Parasit. 1986, 21, 189-203.

Borgsteede FHM: The difference between two strains of Ostertagia ostertagi in resistance to morantel tartate. Int. J. Parasit. 1988, 18, 499-502.

Bjørn H, Sommer C, Schougård H, Henriksen SA, Nansen P: Resistance to benzimidazole anthelmintics in small stongyles of horses in Denmark. Acta vet. scand. 1991, 32, 253-260.

Dash KM, Hall E, Barger IA: The role of arithmetic mean worm egg counts in faecal egg count reduction tests and in monitoring strategic drenching programs in sheep. Aust. vet. J. 1988, 65, 66-68.

Dorny P, Vercuysse J, Berghen P: Resistance of equine small strongyles to benzimidazoles in Belgium. J. vet. Med. B. 1988, 35, 72-75.

Drudge JH, Elam G: Preliminary observations on the resistance of the horse strongyles to phenothiazine. J. Parasit. 1961, 47, 38-39.

Drudge JH, Lyons ET: Newer developments in helminth control and Strongylus vulgaris research. Proc. 155th Meeting Amer. Ass. Eq. Prac. 1965, 378-383.

Drudge JH, Lyons ET: Benzimidazole resistance of equine strongyles. Critical test of six compounds. Amer. J. vet. Res. 1979, 40, 590-594. 
Eysker M, Boersema JH, Kooyman FNJ: Effect of early season ivermectin and pyrantel treatments on strongylid infections in young Shetland ponies in the Netherlands. Vet. Parasit. 1991, 38, 33-39.

Eysker M, Boersema JH, Kooyman FNJ: The effect of ivermectin against inhibited early third stage, late third stage and fourth stage larvae and adult stages of the cyathostomes in Shetlands ponies and spontaneous expulsion of these helminths. Vet. Parasit. 1992, 42, 295-302.

Fisher MA, Jacobs DE, Grimshaw WTR, Gibbons $L M$ : Prevalence of benzimidazole-resistance in equine cyathostome populations in south east England. Vet. Rec. 1992, 130, 315-318.

Gibson TE: The effect of repeated anthelmintic treatment with phenothiazine on the fecal egg counts of housed horses with some observations on the life cycle of Thrichonema spp. in the horse. J. Helmint. 1953, 27, 29-40.

Gibson TE: Some experiences with small daily doses of phenothiazine as a mean of control of the strongylid worms in the horse. Vet. Rec. 1960, 72, 37-41.

Giordano DJ, Tritschler JP, Colers GS: Selection of ivermectin-resistant Trichostrongylus colubriformis in lambs. Vet. Parasit. 1988, 30, 139-148.

Helle $O$ : Tiabendazol og fenbendazol til bekjempelse av parasitter hos unghest. (Treatment against parasites with thiabendazole and fenbendazole in young stallions. Development of resistance in small strongyles). Norsk Vet.Tids. 1986, 98, 623-631.

Ihler CF: Anthelmintika resistens hos gastrointestinale nematoder hos drøvtyggere, gris og hest. (Anthelmintic resistance in gastrointestinal nematodes of ruminants, pig and horses). Norsk Vet. Tids. 1992, 104, 905-914.

Johansen $M V$ : An evaluation of techniques used for the detection of anthelmintic resistance in nematode parasites of domestic animals. Vet. Res. Comm. 1989, 13, 455-466.

Kelly JD, Webster JH, Griffin DL, Whitlock HV, Martin ICA, Gunawan M: Resistance to benzimidazole anthelmintics in equine strongyles. 1. Frequency, geographical distribution and relationship between occurrence, animal husbandry procedures and anthelmintic usage. Aust. vet. J. 1981, 57, 163-171.

Klei TR, Chapman MR, French DD, Taylor HW: Evaluation of ivermectin at an elevated dose against encysted equine cyathostome larvae. Vet. Parasit. 1993, 47, 99-106.
Lacey $E$ : The role of the cytoskeletal protein, tubulin, in the mode of action and mechanism of drug resistance to benzimidazoles. Int. J. Parasit. 1988, 18, 885-936

Lichtenfels JR: Parasites of domestic equids. Proc. helmint. Soc. Wash. 1975. 42. Special issue.

McKenna PB: The detection of anthelmintic resistance by the faecal egg reduction test: An examination of some of the factors affecting performance and interpretation. N. Z. vet. J. 1990, 38, 142-147.

Nilsson $O$, Lindholm A, Christensson $D$ : A field evaluation of anthelmintics in horses in Sweden. Vet. Parasit. 1989, 32, 162-171.

Pereira MC, Kohek I Jr, Campos R, Lima SB, Foz $R P P$ : A field evaluation of anthelmintics for control of cyathostomes of horses in Brazil. Vet. Parasit. 1991, 38, 121-129.

Prichard RK, Hall CA, Kelly JD, Martin ICA, Donald $A D$ : The problem of anthelmintic resistance in nematodes. Aust. vet. J. 1980, 56, 239-251.

Roepstorff A, Bjørn H, Nansen P: Resistance of Oesophagostumum spp. in pigs to pyrantel citrate. Vet. Parasit. 1987, 24, 229-139.

Round MC, Simpson DJ, Haselden CS, Glendinning $E S A$, Baserville RE: Horse strongyle tolerance to anthelmintics. Vet. Rec. 1974, 95, 517-518.

Sangster NC, Kelly JD, Whitlock HW, Gunawan M, Porter CJ: Trichostrongylus colubriformis and Ostertagia circumcincta resistant to levamisole, morantel tartrate and thiabendazole: Occurence of field strains. Res. vet. Sci. 1979, 27, 106-110.

Slocombe JOD, Cote JF: Small strongyles of horses with cross resistance to benzimidazole anthelmintics and susceptibility to unrelated compounds. Can. vet. J. 1977, 18, 212-217.

Taylor MA: Anthelmintic resistance in helminth parasites of domestic animals. Agri. Zool. Rev. 1992, 5, 1-50.

Uhlinger $C A$ : Equine small strongyles: Epidemiology, pathology and control. Comp. Cont. Ed. Pract. Vet. 1991, 13, 863-869.

van Wyk JA, Malan FS: Resistance of field strains of Haemonchus contortus to ivermectin, closantel, rafoxanide and the benzimidazoles in South Africa. Vet. Rec. 1988, 123, 226-228.

Whitlock HV, Kelly JD, Porter CJ, Griffin DL, Martin ICA: In vitro field screening for anthelmintic resistance in strongyles of sheep and horses. Vet.Parasit. 1980, 7, 215-232.

Xiao L, Herd RP, Majewski GA: Comparative efficacy of moxidectin and ivermectin against hypo- 
biotic and encysted cyathostomes and other equine parasites. Vet. Parasit. 1994, 53, 83-90.

\section{Sammendrag}

Anthelmintikaresisstens hos hestens små strongylider: en feltstudie.

Sytten staller, med tilsammen 221 hester, ble unders $\varnothing \mathrm{kt}$ for å observere forekomsten av anthelmintika resistens hos hestens små strongylider. Unders $\varnothing$ kelsen ble utf $\varnothing \mathrm{rt}$ ved hjelp av egg reduksjons test. Fenbendazole, pyrantel pamoat og ivermectin inngikk i unders $\emptyset$ kelsen. Fæcesprøver ble samlet og undersøkt ved behandling samt etter $14 \mathrm{og}$ 90 dager. Resistens for fenbendazole ble funnet i 14 av de 17 undersøkte stallene (eggreduksjon < 95\%). I en stall ble det funnet redusert pyranteleffekt ( $94 \%$ reduksjon), mens det ikke var tegn til resistens overfor ivermectin.

Undersøkelsen ble foretatt på senhøsten og på vinterstid med minimal mulighet for reinfeksjon i løpet av unders $\varnothing$ kelsesperioden. Eggreduksjonen fra behandling til dag 90 etter behandling ble derfor brukt som uttrykk for å sammenlikne pyrantel og ivermectins effekt på cyathostomenes larvestadier. Det ble ikke påvist noen statistisk signifikant forskjell i preparatenes effekt på de små strongyliders larvestadier.

(Received October 7, 1993; accepted October 20, 1994).

Reprints may be requested from: C.F. Ihler, Department of Large Animal Sciences, Norwegian College of Vetrinary Medicine, P.O. Box 8146, Dep., N-0033 Oslo, Norway. 
